\title{
Stability analysis of old underground coal workings using wireless sensor networks
}

\author{
Kumar Dorthi and K Ram Chandar \\ National Istitute of Technology (NITK) \\ Mangalore, India \\ doreti.kumar@gmail.com
}

\begin{abstract}
In recent times, many old underground coal mines are being converted into opencast workings. In the process, removal of waste rock over the old galleries and maintaining a stable slope is a very difficult task. In such cases, continuous slope monitoring may be required. Though there are many methods of slope monitoring, zigbee based wireless sensor network is cost effective and gives real time monitoring. Slope stability depends upon various parameters like bench height, slope angle, berm width, geometry of old workings, thickness of partition, geological discontinuities etc. Here, influence of thickness of partition for a $3 \mathrm{~m}$ height and $4.2 \mathrm{~m}$ wide gallery is assessed using WSN. The data is validated using conventional method of slope monitoring using LVDTs.
\end{abstract}

Keywords-Slope stability; old underground workings; Wireless Sensor Network (WSN), ZigBee; Numerical modelling

\section{INTRODUCTION}

Opencast mining method is a very cost effective method which leads the coal production in India and has a share of more than $83 \%$ [1]. Demand for coal has been increasing day by day to meet the ever increasing demand for various industrial uses. In order to increase the production of coal, various approaches are being used. One of them is, converting the old underground workings into opencast methods, where coal is blocked in the form pillars "Fig.1".

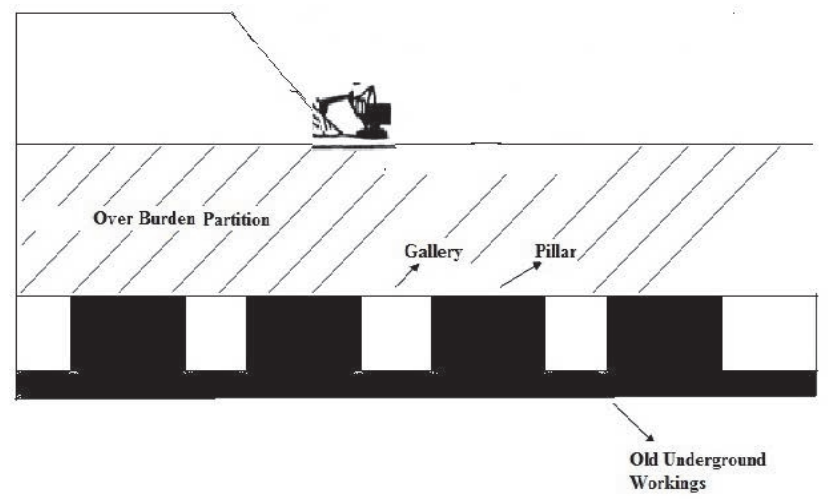

Fig.1. Schematic diagram of old underground galleries with reference to opencast workings.

There are some problems associated with the conversion of old underground coal workings into opencast mines. In some projects, the coal blocked in old workings is being extracted, but due to lack of specific technical guidelines along with the details of strata movement, there were many accidents like falling down of men and machinery into the old galleries and failure of slopes over old underground workings. Further, external factors like blasting in adjacent areas or moment of Heavy Earth Moving Machinery can accelerate the weakening of the partition. Accumulation of water in old galleries is also a major concern [3].

Factors leading to the stability of old underground workings include material properties of the partition, thickness of partition, movement of machinery, geometry of old workings and relative position of the underground workings to the mine bench as the bench progresses. These factors may lead to slope failures and cause damage to equipment and loss of human lives [4].

Slope monitoring is required to assess the slope over old underground galleries. There are many instruments available to assess slope stability but they are restricted to day time only and some instruments require physical presence of persons at the site. Even though, wireless technology based instruments like Slope Stability Radar (SSR) is available but these are highly technology based and very expensive. Wireless Sensor Networks (WSNs) are an emerging technology for low-cost, two way communication and unattended monitoring of a wide range of environment. In WSN also there are many technologies for collecting the data or for communicating the data like ZigBee, Wi-fi, Bluetooth, GSM, etc. Here description is limited to only ZigBee technology.

\section{ZIGBEE BASED WIRELESS SENSOR NETWORK}

Wireless Sensor Networks (WSNs) is one of the major technologies that can be used for real-time monitoring [5, 6]. Wireless Sensor Networks (WSN) refers to a group of spatially dispersed and dedicated sensors for monitoring, recording the physical conditions of the environment and organizing the collected data at a central location [7]. The WSN consists of mainly three components: sensor node, sink node or gateway and processing unit "Fig.2". Sensor Node is capable of gathering, processing sensory information and communicating with other connected nodes in the network. Sink Node is also known as gateway and it is responsible for receiving the sensor data and retransmitting data to the user or processing unit through 


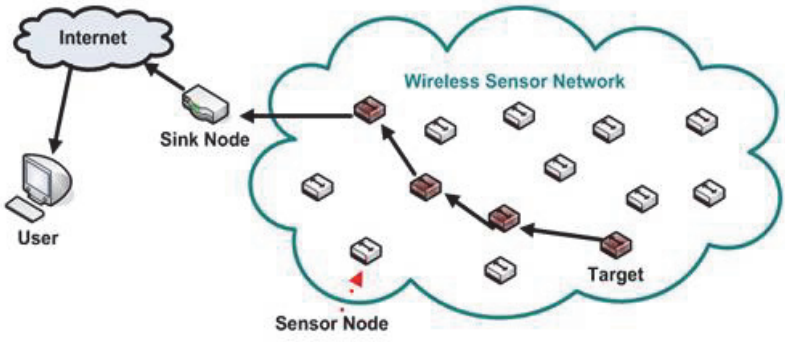

Fig.2. Structure of Wireless Sensor Networks (WSNs)

internet. It consists of four components: sensing unit, micro controller unit, transceiver unit and battery unit "Fig. 3".

- Sensing Unit: A sensing unit comprises the sensor and analog-to-digital converter. The sensor is responsible for detecting and collecting the data which represents the analog signals. The analog-to-digital converter converts the analog signals into digital data and sends the data to the processing unit.

- Micro Controller: It is also known as processing unit comprises the processor and the storage unit. Storage unit stores the collected data. Processor processes the data according to the predefined program code.

- Transceiver Unit is responsible for the communication among sensor nodes.

- Battery Unit provides the electric power and it is the most important unit of sensor node.

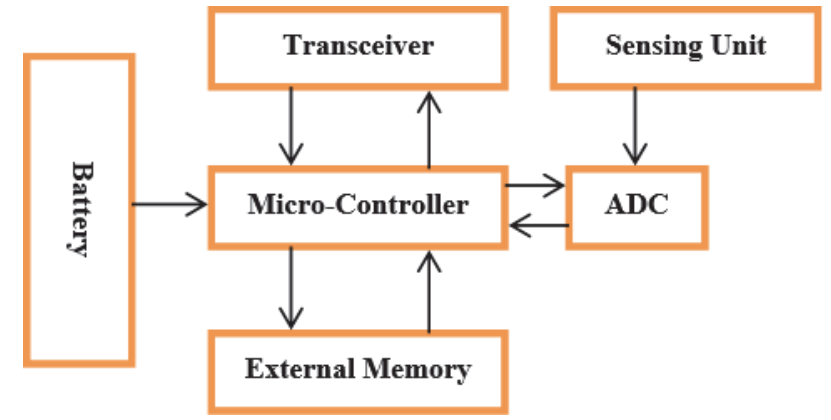

Fig.3. Structure of sensor node

Processing Unit is the CPU of a wireless sensor node. It is also known as controller unit. The most commonly used controller in wireless sensor node is the micro-controller because its features like small size, low power consumption and ease of programming, and many of the microcontrollers have an embedded Analog to Digital Converter (ADC) in them. Processing unit is responsible to process the sensor data, executes the communication protocols, signal processing and controls the sensors.

Zigbee is a short distance, low- complexity, low power consumption, low data rate, low-cost, two-way and wireless communication solution. The transmission distance of Zigbee is over $10-100 \mathrm{~m}$ and the operating frequency band is ISM frequency band of $868 \mathrm{MHz}, 915 \mathrm{MHz}$ and $2.45 \mathrm{GHz}$. The $2.45 \mathrm{GHz}$ is universal industrial and medical standard frequency band in the world, providing 16 channels and transmission speed of $250 \mathrm{kbps}$. ZigBee alliance is responsible for ZigBee standard and IEEE which is responsible for IEEE 802.15.4. It is like TCP/IP using IEEE 802.11 b network specifications. ZigBee alliance defines the network, security and application layers whereas IEEE 802.15.4 defines the physical and media access control layers. ZigBee network can have up to 65335 devices. The distance between these devices can be up to $50-100 \mathrm{~m}$ and each node can relay data to other nodes in the network. This results in very big network which are capable of covering significant distances [8]. Zigbee is the hardware module used for communication purpose. It consists of transmitter and receiver. Higher amount of data with higher speed can be sent through zigbee. It does not require external signal for communication, so zigbee modules can be used anywhere even in forests, hill stations etc. One zigbee can communicate with any other zigbee present in the surrounding area. In Zigbee, the transmitter transmits the data without having delay. The receiver automatically receives data transmitted from transmitter without data loss. In this zigbee, there is no need of human intervention to send or receive data [9].

\section{FIELD INVESTIGATIONS}

A case study is taken up in a large opencast coal mine where old underground workings are being converted into opencast mine in south India. Conversion of old underground mine into surface mine is carried out in a series of steps. It starts with preliminary survey of the area and finally the extraction of pillars is undertaken.

The detailed off-set survey is conducted. In this, old underground galleries are identified and marked with stone dust on the surface. After demarcation, drilling is done to ascertain proved parting and recorded. Marking is done to prevent the bogging down of men and machinery into the gallery due to the movement of the HEMM over the partitions "Fig.4".

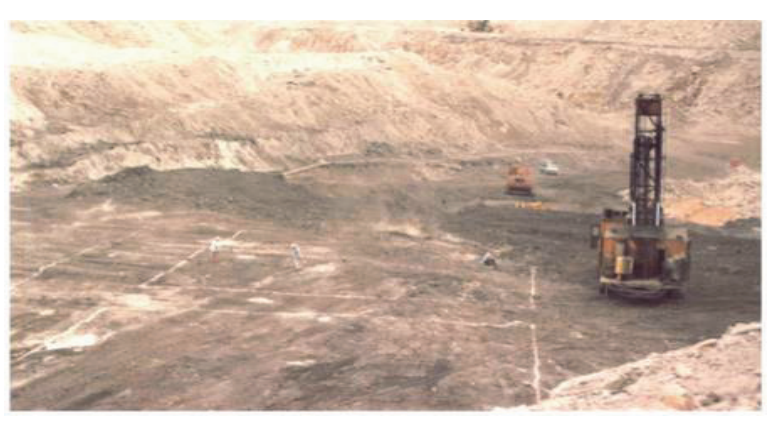

Fig.4. Marking with stone dust on the surface of the workings

The overburden is drilled to above the roof of the galleries and blasted, leaving some partition above the coal seam. Dragline removes the broken overburden. The dozer dozes overburden until the top coal seam is obtained. It prepares the top surface of the coal seam for drilling. After drilling the coal seam, the blasted coal is loaded.

\section{A. Field monitoring using zigbee based WSN}

This paper mainly intends to measure the deformation in partition over old underground workings due to the 
movement of Heavy Earth Moving Machinery (HEMM) "Fig.5".

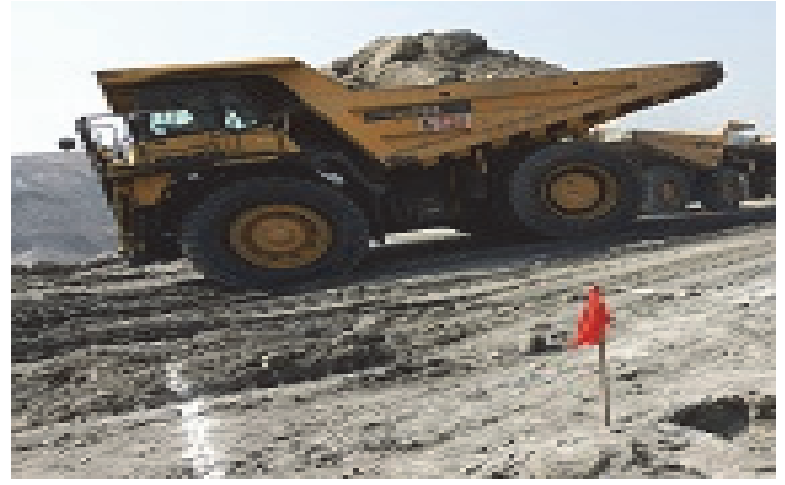

Fig.5.Movement of HEMM above old underground galleries in an opencast mine

In order to monitor deformation, a geo-physical sensor such as Linear Variable Differential Transformer (LVDT) was used. LVDT of range $50 \mathrm{~mm}$ was mounted on the metal scale and installed at different monitoring points, namely A, $\mathrm{B}$ and $\mathrm{C}$ above old underground galleries of height $3 \mathrm{~m}$ and width $4.2 \mathrm{~m}$ by digging a pit of $15 \times 15 \times 15 \mathrm{~cm}$ in the overburden Fig.6 and Fig. 7.

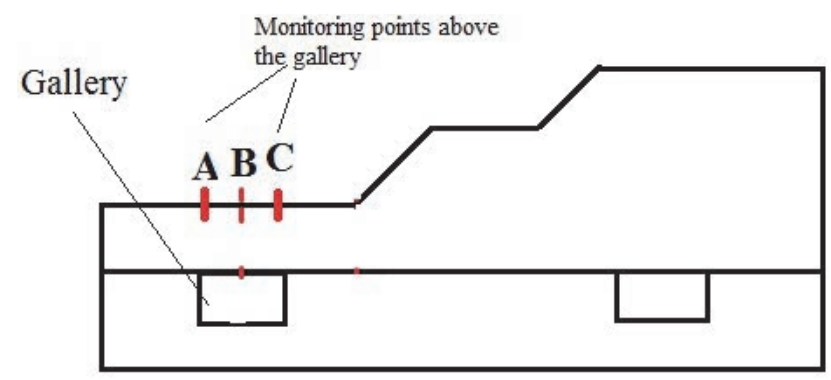

Fig. 6. Schematic diagram of monitoring points in the site

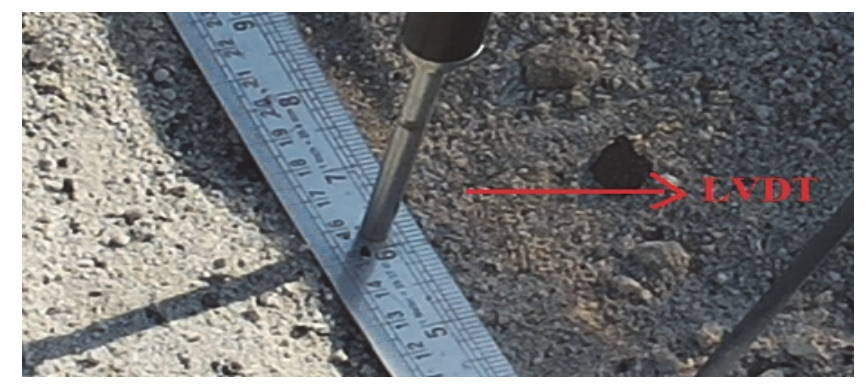

Fig. 7. Installation of LVDT

LVDT was connected to Wireless Data Acquisition System (WDAQ) which consists of micro controller, Zigbee transceiver, Analog-to-Digital Converter (ADC), Battery "Fig.8". Zigbee was used as wireless data transmission for monitoring of stability of slope over old underground workings. It consists of transmitter and receiver. The transmitter transmitted the data from sensor node without having delay. Zigbee wireless receiver received the data displayed on remote system which was located at $100 \mathrm{~m}$ away displayed from the monitoring point "Fig.9".

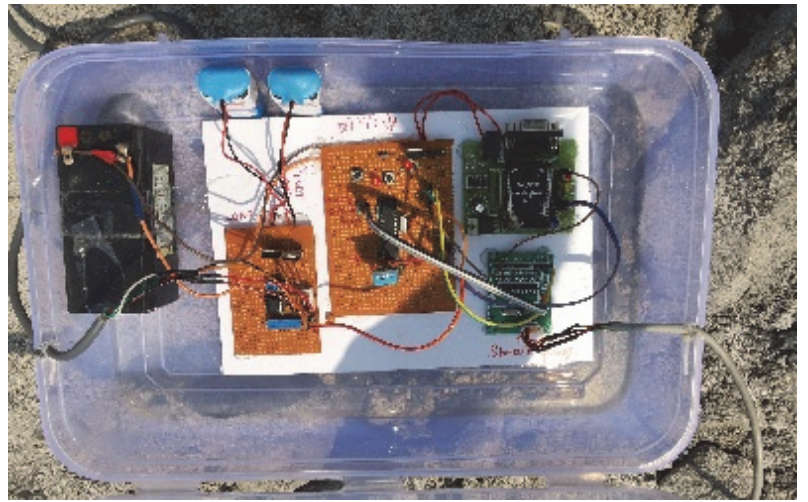

Fig.8.Wireless data acquisition system

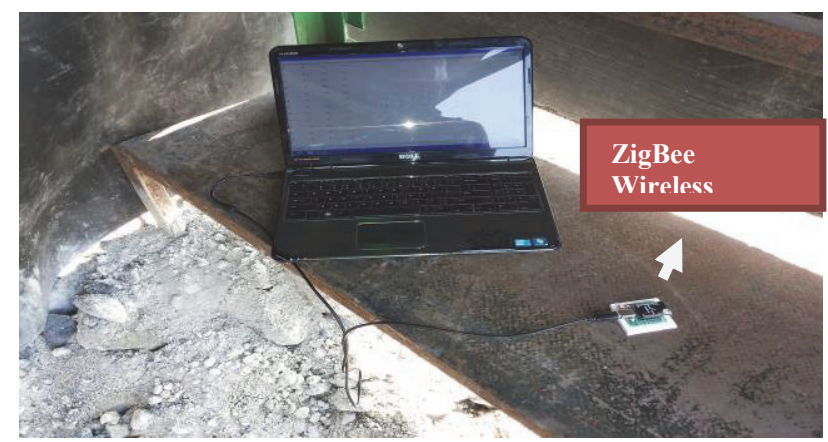

Fig. 9. Remote monitoring using Zigbee based WSN.

Partition thicknesses of $4 \mathrm{~m}, 6 \mathrm{~m}, 8 \mathrm{~m}, 10 \mathrm{~m}$ and $12 \mathrm{~m}$ were considered for monitoring deformation. Deformation was recorded and processed with help of a self-developed software in CPP language. Sensors data was taken from different monitoring points $\mathrm{A}, \mathrm{B}$ and $\mathrm{C}$ above the gallery and output data is tabulated in Table I.

The variation of deformation with change in partition thickness at different monitoring points $\mathrm{A}, \mathrm{B}$ and $\mathrm{C}$ above the gallery is plotted in "Fig.10". From "Fig.10", it can be observed that the values of deformation decreased as the partition width is increased. Maximum deformation was observed at monitoring point $\mathrm{B}$ than monitoring point $\mathrm{A}$ and $\mathrm{C}$, as point $\mathrm{B}$ is center of the gallery.

Table i. VARiation of Deformation with Change in Partition THICKNESS USING WSN

\begin{tabular}{|c|c|c|c|}
\hline \multirow{2}{*}{$\begin{array}{l}\text { Partition } \\
\text { Thickness } \\
(\boldsymbol{m})\end{array}$} & \multicolumn{3}{|c|}{ Deformation (mm) using WSN } \\
\cline { 2 - 4 } & $\begin{array}{l}\text { Monitoring } \\
\text { point A }\end{array}$ & $\begin{array}{l}\text { Monitoring } \\
\text { point B }\end{array}$ & $\begin{array}{l}\text { Monitoring point } \\
\text { C }\end{array}$ \\
\hline 4 & 1.98 & 2.45 & 2.03 \\
\hline 6 & 1.87 & 2.24 & 1.96 \\
\hline 8 & 1.65 & 1.91 & 1.83 \\
\hline 10 & 1.57 & 1.78 & 1.62 \\
\hline 12 & 1.37 & 1.64 & 1.48 \\
\hline
\end{tabular}

In order to validate the data generated using WSN, the set of instruments were connected to a conventional data logger 


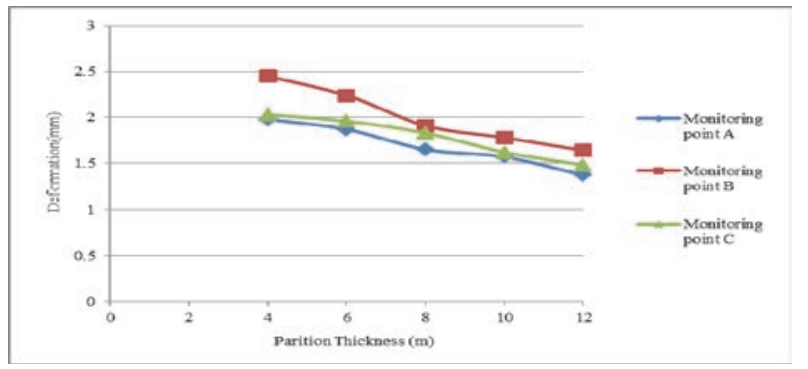

Fig.10. Deformation in partition using WSN

which is AH391-4 Channel with LED display "Fig.11". ADsof software was used to process the data as shown in "Fig.12".

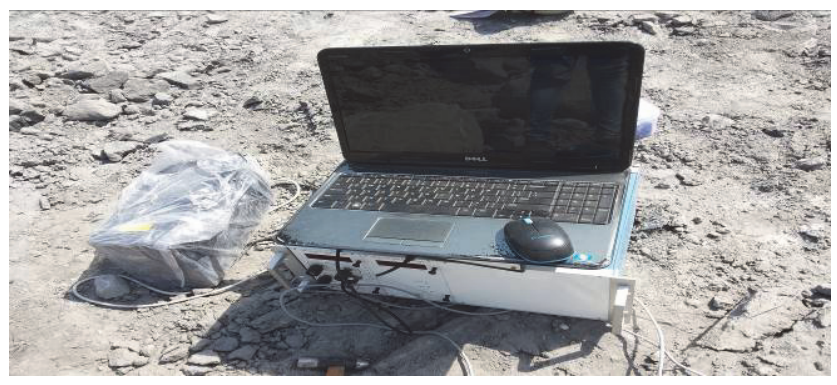

Fig.11. AH491-4 Channel data logger in site

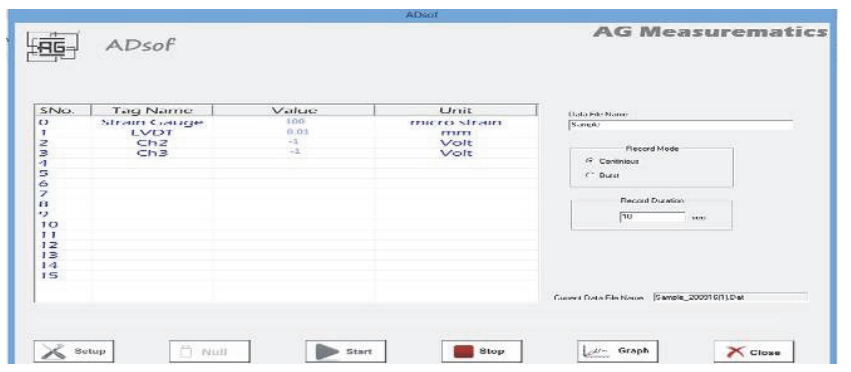

Fig.12. Snapshot from Software module of data logger

The data obtained using data logger is given in "Table II".

TABle il. Variation of Ddeformation with Change in Ppartition TTHICKNESS USING DATA LOGGER

\begin{tabular}{|c|c|c|c|}
\hline \multirow{2}{*}{$\begin{array}{c}\text { Partition } \\
\text { Thickness(m) }\end{array}$} & \multicolumn{3}{|c|}{ Deformation (mm) using Data logger } \\
\cline { 2 - 4 } & $\begin{array}{l}\text { Monitoring } \\
\text { point A }\end{array}$ & $\begin{array}{l}\text { Monitoring } \\
\text { point B }\end{array}$ & $\begin{array}{l}\text { Monitoring } \\
\text { point } \text { C }\end{array}$ \\
\hline 4 & 1.81 & 2.20 & 1.85 \\
\hline 6 & 1.66 & 1.90 & 1.72 \\
\hline 8 & 1.35 & 1.62 & 1.45 \\
\hline 10 & 1.29 & 1.55 & 1.31 \\
\hline 12 & 1.22 & 1.44 & 1.33 \\
\hline
\end{tabular}

The variation of deformation with change in partition thickness at different monitoring points $\mathrm{A}, \mathrm{B}$ and $\mathrm{C}$ above the gallery is plotted in "Fig.13". It can be observed that the values of deformation decreased as the partition width is increased. Maximum deformation was observed at monitoring point $\mathrm{B}$ than monitoring point $\mathrm{A}$ and $\mathrm{C}$.

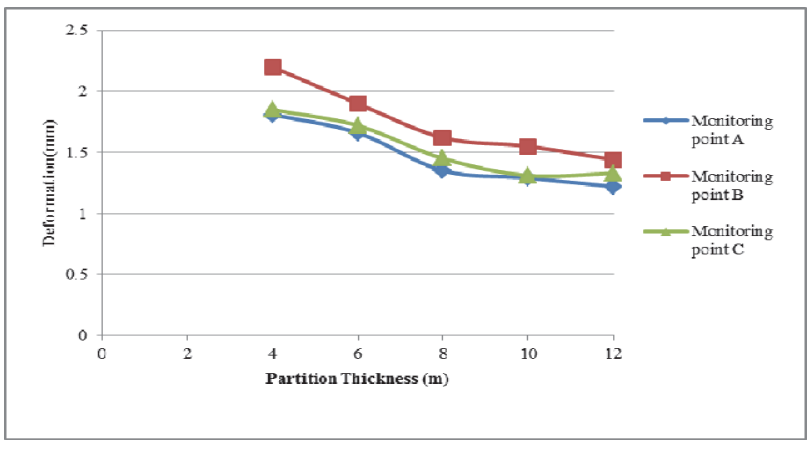

Fig.13. Deformation in partition using data logger

Maximum deformation observed at monitoring point $\mathrm{B}$ in both cases (WSN and Data logger). A comparison plot is given in "Fig.14".

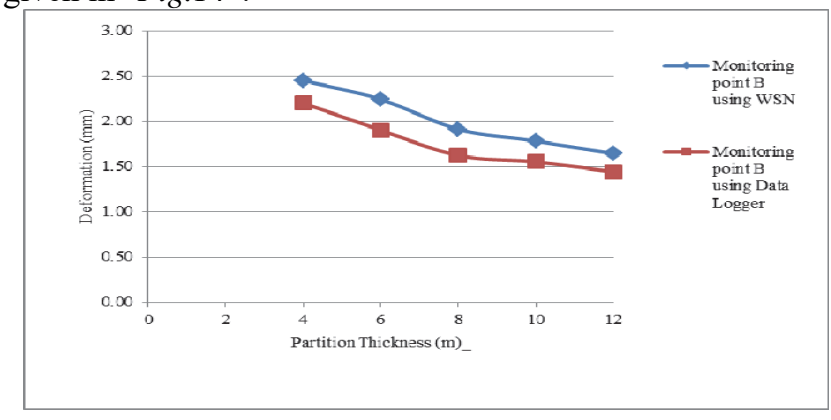

Fig.14. Comparison of deformation in partition from both WSN and Data logger

From "Fig.14", it can be observed that deformation observed by WSN is more than conventional data logger. Maximum deformation observed by data logger is $2.20 \mathrm{~mm}$, whereas $2.45 \mathrm{~mm}$ was observed by WSN for $4 \mathrm{~m}$ partition thickness. The variation is around $5-15 \%$ which is acceptable. This proves that the ZigBee based WSN technology is giving accurate results.

To further validate the studies, numerical modeling was carried out under similar fiend conditions.

\section{NUMERICAL MODELLING}

Numerical modelling technique is an efficient method that is widely used in various fields of science \& engineering including rock engineering. Numerical modeling for rock mechanics has been developed for the design of rock engineering structures under different conditions for different purposes. Numerical modelling techniques provide an approximate solution to problems which otherwise cannot be solved by conventional methods. Numerical modelling is used to investigate a variety of problems in rock slope behavior, underground mining and tunneling engineering which can assist the geo-technical engineer in designing underground excavations, surface excavations and support systems $[10,11]$.

Stability of old underground workings is simulated using static structure module of ANSYS15 workbench. To study the effect of partition width over dimensions of old 
underground workings in opencast mine, 3D models of mine benches were developed "Fig. 15".

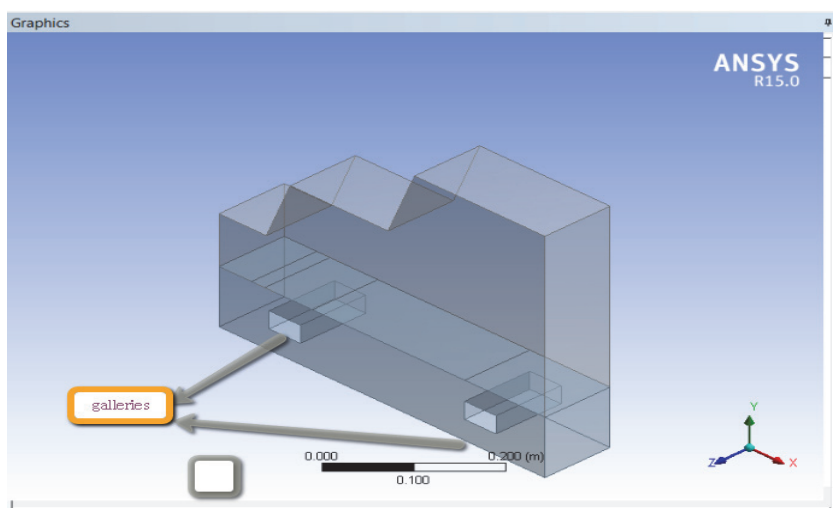

Fig.15. The 3D model of the mine benches over underground galleries

\section{A. Design parameters of model}

The field parameters incorporated in the model is as follows:

- Overburden (Sandstone) partition considered for study is $4 \mathrm{~m}, 6 \mathrm{~m}, 8 \mathrm{~m}, 10 \mathrm{~m}$ and $12 \mathrm{~m}$.

- Thickness of Coal seam is $7 \mathrm{~m}$.

- Width of gallery is $4.2 \mathrm{~m}$ and height of gallery is $3 \mathrm{~m}$, separated by a centre to centre distance of $30 \mathrm{~m}$ pillars and bench slope angle is $55^{\circ}$.

- The contact between the sandstone and coal layers is smooth. The models were assigned with different material properties based on field conditions and laboratory experiments carried out on some samples "Table III".

- The gravitational force acts along the centre of gravity of the combined mass.

TABLE III. MATERIAL PPROPERTIES

\begin{tabular}{|l|c|c|}
\multicolumn{1}{|c|}{ Property } & Sandstone & Coal \\
\hline Young's Modulus (GPa) & 25 & 3 \\
Density $(\mathrm{kg} / \mathrm{m} 3)$ & 2450 & 1500 \\
\hline Poisson's Ratio & 0.25 & 0.22 \\
Tensile Yield Strength (MPa) & 0.8 & 3.9 \\
\hline Compressive Yield Strength (MPa) & 150 & 25 \\
\hline
\end{tabular}

- The HEMM stress was placed at different positions (Monitoring point $\mathrm{A}, \mathrm{B}$ and $\mathrm{C}$ ) above the gallery and the Stress exerted by the HEMM is taken as 5.91 X 106 N/m2 "Fig.16".

- A rigid support was applied to the base of the model.

- Frictionless supports are implied on either side of the model.

Models were developed to study the effect of partition thickness by keeping other parameters such as slope angle, material properties, position of HEMM etc., constant. A typical deformation along the y-axis is shown in "Fig.17".

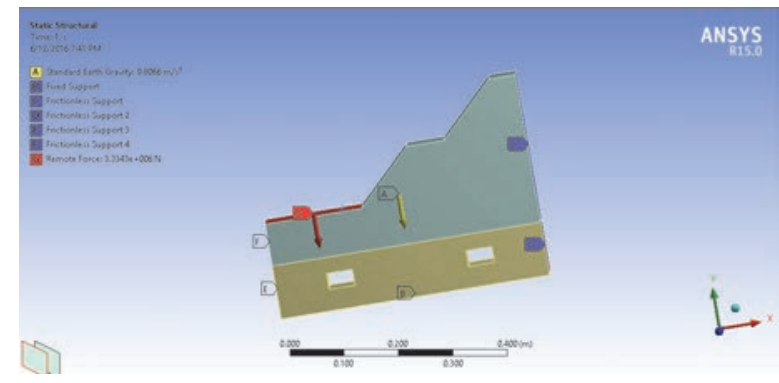

Fig.16. Applications of stresses and boundary conditions to the model

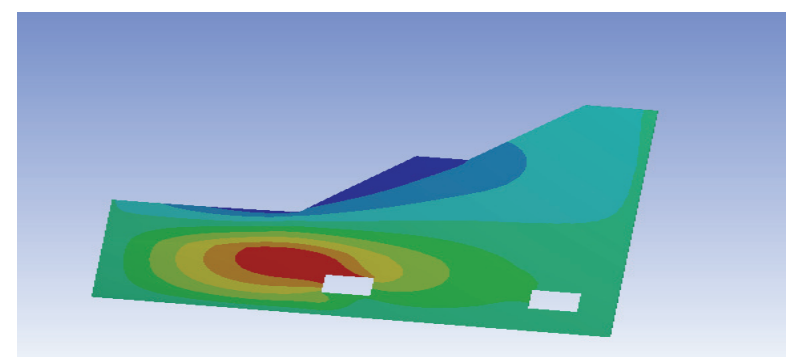

Fig.17. Directional deformation along y-axis due to HEMM movement

\section{B. Deformation}

In order to study the directional deformation along the $y$ axis (vertically) of old underground galleries, models were developed with partition thickness of $4 \mathrm{~m}, 6 \mathrm{~m}, 8 \mathrm{~m}, 10 \mathrm{~m}$ and $12 \mathrm{~m}$. Deformation values of different partition thicknesses of $4 \mathrm{~m}, 6 \mathrm{~m}, 8 \mathrm{~m}, 10 \mathrm{~m}$ and $12 \mathrm{~m}$ are given below in "Table $I V^{\prime \prime}$.

Table iV. Variation of Deformation With Change In Partition THICKNESS FOR GALLERY HEIGHT OF 3M AND WIDTH OF 4.2M

\begin{tabular}{|c|c|c|c|}
\hline \multirow{2}{*}{$\begin{array}{c}\text { Partition } \\
\text { Thickness } \\
\text { (m) }\end{array}$} & \multicolumn{3}{|c|}{ Deformation (mm) } \\
\hline & Point $A$ & Point $B$ & Point $C$ \\
\hline 4 & 2.05 & 2.75 & 2.13 \\
\hline 6 & 1.86 & 2.64 & 1.95 \\
\hline 8 & 1.55 & 2.25 & 1.67 \\
\hline 10 & 1.47 & 1.98 & 1.52 \\
\hline 12 & 1.24 & 1.82 & 1.37 \\
\hline
\end{tabular}

The variation of deformation with change in gallery width and partition thickness for gallery height of $3 \mathrm{~m}$ and width of $4.2 \mathrm{~m}$ is shown in "Fig.18". From "Fig.18", it can be observed that minimum and maximum deformation at center of the gallery (point B) is 1.82 and 2.85 for partition

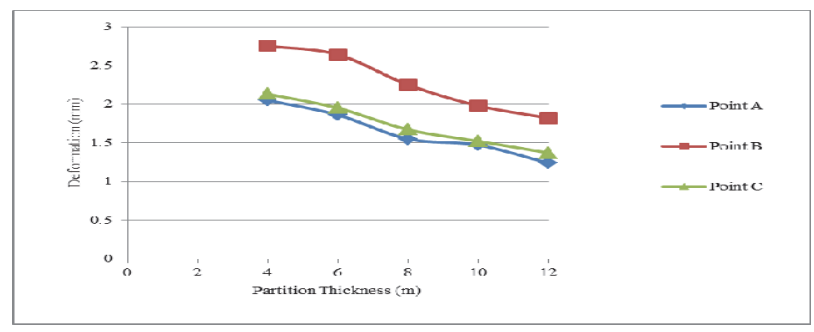

Fig. 18. Deformation Vs partition thickness at different points 
thickness of $12 \mathrm{~m}$ and $4 \mathrm{~m}$ respectively. It can be observerd that deformation is decreased with increasing partition thickness.

\section{COMPARISON STUDIES}

Deformation values of different partition thicknesses monitored at point B (surface center of the gallery) for gallery height of $3 \mathrm{~m}$ and gallery width of $4.2 \mathrm{~m}$ from data logger, WSN and numerical modelling is tabulated in "Table $I V^{\prime \prime}$.

TABlE IV. COMPARISON OF DEFORMATION OF DATA LOGGER, NUMERICAL MODELING AND ZIgBeE BASED WSN

\begin{tabular}{|c|c|c|c|}
\hline $\begin{array}{c}\text { Partition } \\
\text { Thickness } \\
(\boldsymbol{m})\end{array}$ & Using WSN & $\begin{array}{c}\text { Using Data } \\
\text { Logger }\end{array}$ & $\begin{array}{c}\text { Using } \\
\text { Numerical } \\
\text { Modelling }\end{array}$ \\
\cline { 2 - 4 } & 2.45 & 2.20 & 2.75 \\
\hline 4 & 2.24 & 1.90 & 2.64 \\
\hline 6 & 1.91 & 1.62 & 2.25 \\
\hline 8 & 1.78 & 1.55 & 1.98 \\
\hline 10 & 1.64 & 1.44 & 1.82 \\
\hline 12 & & & \\
\hline
\end{tabular}

The comparison of deformation in partition of numerical modelling, WSN and Data logger is plotted in "Fig.19". From fig.19, it can be observed that the trend of deformation in partition is decreased with increasing partition thickness and vice versa. Minimum and maximum deformation using numerical modelling, WSN and data logger is $1.82 \mathrm{~mm}$, $2.75 \mathrm{~mm}, 1.64 \mathrm{~mm}, 2.45 \mathrm{~mm}$ and $1.44 \mathrm{~mm}, 2.20 \mathrm{~mm}$ for partition thickness $12 \mathrm{~m}$ and $4 \mathrm{~m}$ respectively. Deformation values of numerical modelling are more than the data logger and WSN for all partition thicknesses.

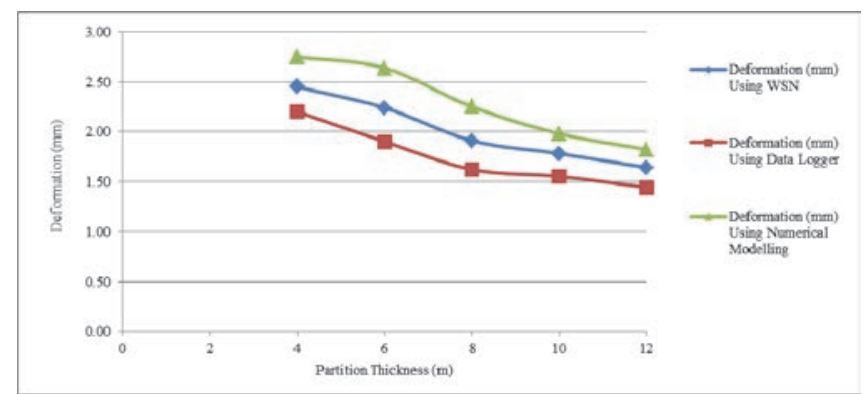

Fig.19. Comparison of deformation in partition at B with different methods

\section{CONCLUSIONS}

Based on the study following conclusions are drawn:

Minimum and maximum deformation using WSN are $1.37 \mathrm{~mm}$ and $2.45 \mathrm{~mm}$ for partition thickness $12 \mathrm{~m}$ and $4 \mathrm{~m}$ respectively. Similarly, minimum and maximum deformation using data logger is $1.22 \mathrm{~mm}$ and $2.20 \mathrm{~mm}$ for partition thickness $12 \mathrm{~m}$ and $4 \mathrm{~m}$ respectively and $1.82 \mathrm{~mm}$ and $2.75 \mathrm{~mm}$ in case of numerical modelling for partition thickness $12 \mathrm{~m}$ and $4 \mathrm{~m}$ respectively.

Deformation in partition thickness is higher at monitoring point $\mathrm{B}$ which is exactly surface center of gallery, than monitor points A and C. It is observed that the deformation in partition decreases with increase in partition thickness.

Comparison study has been done among WSN, data logger and numerical modelling. The data obtained from WSN is very close to other two methods, confirming that WSN is giving accurate results.

\section{REFERENCES}

[1] Ministry of Coal, "Coal Statistics", 1-82, 2015. http://coal.nic.in/sites/upload_files/coal/files/coalupload/provisional1 314_0.pdf (Accessed on 15th Dec 2015).

[2] D. Kumar, K. Ram Chandar and Alston D'Souza., "Effect of partition of overburden on stability of old underground workings", Proc. INDORCOK-16, IIT Bombay, 17-18 June, 2016, 950-970.

[3] V.R. Sastry and K. Ram Chandar, "'Stability analysis of highwallcase study of an opencast coal mining project", Mining Engineers Journal, Vol-12, No.4, 18-24, Nov-2010.

[4] K. Ram Chandar, Chiranth Hegde, Mohan Yellishetty and B. Gowtham Kumar, "Classification of stability of highwall during highwall mining: a statistical adaptive learning approach", Int. Jl. Geotechnical \& Geological Engineering, Vol- 33, Issue-3, 511-521 (Geotech Geol Eng DOI 10.1007/s10706-014-9836-6), June- 2015.

[5] Dave Ta Teh Chang, Yuh-Show Tsai and Kai-Chun Yang, "Study of real-time slope stability monitoring system using wireless sensor network", Telkomnika, Vol.11, No.3, pp. $1478 \sim 1488$, e-ISSN:2087278X, 2013.

[6] D. Kumar and K. Ram Chandar, "Application of wireless sensor networks in slope stability monitoring - a critical review", The Indian Mining \& Engineering Journal, Vol. 55 No. 03, pp 29-32, 2016.

[7] P. Baronti, P. Pillai, V.W.C. Chook, S. Chessa, A. Gotta and Y.F. Hu, "Wireless sensor networks: a survey on the state of the art and the 802.15.4 and zigbee standards", Computer Communications, 30(7), $1655-1695,2007$.

[8] T. de Almeida Oliveira and E.P. Godoy, "ZigBee wireless dynamic sensor networks: feasibility analysis and implementation guide",IEEE Sensors Journal, 16(11), 4614-4621, 2016. http://doi.org/10.1109/JSEN.2016.2542063

[9] ShizhuangLin, JingyuLiu, YanjunFang and U.W. Wuhan, "Zigbee based wireless sensor networks and its applications in industrial", IEEE International Conference on Automation and Logistics, 18-21, pp.1979-1983, 2007.

[10]E. Eberhardt, "Rock slope stability analysis-utilization of advanced numerical techniques", Geological Engineering/Earth and Ocean Sciences, 2003.

[11]K. Ram Chandar and B. Gowtham Kumar, "Effect of width of highwall mining gallery on stability of highwall", Int. Jl. Mining and Mineral Engineering, Vol. 5, No. 3, 212-228, 2014.(Published by Inderscience) (DOI: 10.1504/IJMME.2014.064481). 